\title{
A scientific critique of the two-degree climate change target
}

\author{
Reto Knutti ${ }^{1 \star}$, Joeri Rogelj ${ }^{1,2}$, Jan Sedláček' and Erich M. Fischer ${ }^{1}$
}

The world's governments agreed to limit global mean temperature change to below $2^{\circ} \mathrm{C}$ compared with pre-industrial levels in the years following the 2009 climate conference in Copenhagen. This $2^{\circ} \mathrm{C}$ warming target is perceived by the public as a universally accepted goal, identified by scientists as a safe limit that avoids dangerous climate change. This perception is incorrect: no scientific assessment has clearly justified or defended the $2^{\circ} \mathrm{C}$ target as a safe level of warming, and indeed, this is not a problem that science alone can address. We argue that global temperature is the best climate target quantity, but it is unclear what level can be considered safe. The $2^{\circ} \mathrm{C}$ target is useful for anchoring discussions, but has been ineffective in triggering the required emission reductions; debates on considering a lower target are strongly at odds with the current real-world level of action. These debates are moot, however, as the decisions that need to be taken now to limit warming to 1.5 or $2^{\circ} \mathrm{C}$ are very similar. We need to agree how to start, not where to end mitigation.

$\square$ overnment representatives are meeting once again at the international climate talks in Paris in December 2015, with the aim of deciding on new steps towards preventing dangerous man-made climate change. Much of the disagreement among the parties can be linked to differing national priorities and burden sharing - that is, how much each country has to contribute to a solution, for example, in terms of emission reductions, financial and technological support, or in compensation payments for loss and damages. The means with which to restrict warming to below the $2{ }^{\circ} \mathrm{C}$ limit are not the only issues discussed in policy circles ${ }^{1,2}$ and by the public ${ }^{3,4}$, the adequacy of the target itself is also debated.

The ultimate objective of the United Nations Framework Convention on Climate Change (UNFCCC), established back in 1992, is "to stabilize greenhouse gas concentrations in the atmosphere at a level that would prevent dangerous anthropogenic interference with the climate system" ${ }^{\prime 5}$. But it neither specifies what concentration level that would be, nor how to assess what is "dangerous". Following the Copenhagen Accord in 2009, the UNFCCC formally decided in 2012 to pursue actions in line with a $2{ }^{\circ} \mathrm{C}$ global temperature increase target ${ }^{6}$. This target was a political decision informed by science, but no scientific assessment ever defended or recommended a particular target. Policymakers like to hide behind scientific evidence 7 , ask for 'actionable science' and claim to make 'science-based decisions'. Some argue that this process "has more in common with a salad bar - where people pick and choose convenient studies - than with the balanced search for truth that science aspires to" 8 .

Ultimately, the $2{ }^{\circ} \mathrm{C}$ target is a political consensus that takes into account what policymakers at that time considered to be both realistically achievable and tolerable. It is high time for a scientific assessment of the question whether global mean temperature is a meaningful quantity, and if so, how science can contribute to deciding what level most appropriately reflects the UNFCCC's ultimate objective.

\section{Global temperature as a target}

A meaningful target for limiting warming must, first and foremost, be clearly related to what should be achieved. In addition, it needs to be observed with sufficient accuracy, both today and back in the past; a robust understanding is required of how humans have affected the level of warming so far and how we can control it; and finally it should be easy to communicate.

Global mean surface temperature largely meets these requirements: its relationship to climate impacts at the global scale is complex, but undisputed. For more than a century, global mean temperatures have been well observed. Temperature changes since the industrial revolution are mostly attributable to the burning of fossil fuels and we have a robust understanding of additional causes of past trends in global temperatures as well as of their temporal and spatial variability. Finally, global temperature change is approximately linearly related to the total anthropogenic $\mathrm{CO}_{2}$ emitted since the industrial revolution, and is therefore directly linked to human action. However, a long-term surface temperature target does not capture ocean acidification, rates of change or the energy uptake of the whole planet, for example.

There are many other possible targets, such as limits to atmospheric greenhouse gas (GHG) concentrations, energy uptake, sealevel rise, ocean acidification, rates of temperature change, regional climate change, specific unacceptable local impacts, avoidance of tipping points such as the loss of the Greenland ice sheet, emission reductions in a particular year, timing of global zero emissions, or even economic quantities such as the cost of impacts (see Box 1 for an assessment of some quantities). Indeed any other quantity, or a combination of several quantities ${ }^{9}$, could in principle be considered as a target. But the more local and the more specific the formulation of targets, the higher the uncertainty in future projections and the poorer their historical observational record. Finally, even local targets require aggregation to become actionable at the global level. Combining multiple targets is possible but opens another debate on which targets to pick, and how to weigh or combine them.

In terms of alternative temperature-based targets, rates of change in global surface temperature have been discussed ${ }^{10,11}$, for example, because adaptation of infrastructure is generally easier and less costly with more time, and ecosystems might be able to shift their habitats if the climate changes more slowly. Rates of change over short periods are strongly affected by natural climate variability ${ }^{12}$, 


\section{Box 1 | Alternative target quantities.}

GHG concentrations in the atmosphere. An early proposed target was stabilization of atmospheric GHG concentrations ${ }^{52-54}$, and some still advocate such a target (for example, the nongovernmental movement 350.org). GHG concentrations are well-observed, however, impacts do not track them closely. Temperature and therefore impacts would continue to change for many decades even under constant atmospheric GHG concentrations. Different GHGs have different sources and lifetimes and would need to be aggregated. The warming in response to GHGs is uncertain, and other local forcings (from aerosols or land use) also affect the climate. Radiative forcing as an aggregated quantity of all radiatively active species avoids some of these issues, but is a model-derived quantity that cannot directly be measured.

Global energy uptake. An attractive quantity from a physical point of view would be global energy uptake by the entire climate system, rather than just the atmosphere. More than $90 \%$ of the net energy uptake of the planet ends up in the oceans, leaving only a small fraction in the atmosphere. But observational estimates of global ocean heat content are short and loaded with uncertainty, particularly before the 2000s. Warming of the entire ocean depth is also delayed by hundreds of years relative to the surface and is largely unrelated to impacts on land.

Global sea-level rise. The thermal expansion of seawater and the melting of ice sheets and glaciers leads to global sea-level rise. As a result of the long timescales in the disintegration of the Greenland and Antarctic ice sheets, sea level would continue to increase for thousands of years even with constant or declining surface temperatures, making its link to other impacts weak. In addition, uncertainties in long-term sea-level rise are still very large, which reduces its usefulness as a target metric.

so setting an upper bound for those is problematic. Limiting longerterm trends is an option that, maybe unjustifiably so, has not gotten much attention so far. Minimizing rates of change would also favour rapid mitigation.

In summary, global surface temperature is the indicator that meets most of the requirements for a climate target, and it has already garnered widespread support. One potential drawback is that the baseline - pre-industrial conditions - is poorly defined. 'Pre-industrial' in the IPCC ${ }^{13}$ assessments refers to 1750 , yet there is no instrumental record of global temperature before about 1850, and $\mathrm{CO}_{2}$ emissions, in particular from land use and land-use changes, are poorly known. Setting a different base period, for example, 1850-1900, would make sense scientifically. However, applying a different base period affects how historical emissions are accounted for in a country's total (referred to as historical responsibility), and is therefore debated.

\section{Global warming and local climate change impacts}

A change in global temperature does not translate into local impacts in a straightforward manner. Similarly, criteria for judging whether a local change constitutes 'dangerous interference' are not obvious.

Large-scale patterns of surface warming - and as a consequence, many other variables - scale approximately linearly with the magnitude of global mean surface temperature change ${ }^{14}$, with slight deviations when the system approaches equilibrium. Similar changes in the physical system occur earlier for higher GHG emission rates ${ }^{15}$ (Fig. 1). Aggregated quantities, such as the relative change of global precipitation, scale remarkably linearly with temperature
(Fig. 2a). Even the large-scale changes in some extreme weather events, for example, the warming of the hottest days or the increase in the magnitude of heavy precipitation, scale approximately with mean temperature.

As a result, however, the number of events exceeding a threshold generally increases non-linearly. For example, the number of very hot days exceeding a percentile-based threshold increases globally about six-fold for a $1{ }^{\circ} \mathrm{C}$-warmer world, but more than 20 -fold for a $2{ }^{\circ} \mathrm{C}$-warmer world ${ }^{16}$ (Fig. 2b). In cases where physiological thresholds play a role (for example, public health, plants or ecosystems), the impacts are therefore likely to be strongly nonlinear. Indeed, this is a general feature of many impacts: damages from storms, floods, droughts, and so on. Such impacts are typically small for moderate events and then increase rapidly. There are also important limits to adaptation; at $4{ }^{\circ} \mathrm{C}$ the impact risk is much higher than at $2{ }^{\circ} \mathrm{C}$, but the potential for risk reduction through adaptation is not much higher at $4{ }^{\circ} \mathrm{C}$ than at $2{ }^{\circ} \mathrm{C}$ (ref. 17).

Some changes may be abrupt in time, or exhibit threshold behaviour as a function of equilibrium temperature. Long-term sea-level rise at multi-centennial timescales, and the damage and cost associated with it, for example, is likely to be much larger above $2^{\circ} \mathrm{C}$ as a result of the potential disintegration of the Greenland ice sheet (Fig. 2c). Sea-ice cover in the whole Northern Hemisphere scales approximately with temperature ${ }^{18}$, but locally, abrupt and large changes are possible (Fig. 2d), partly as a result of large natural variability superimposed on a long-term trend. Large-scale tipping points and thresholds in the climate itself (for example, a dieback of the Amazon rainforests, a collapse of the Atlantic Meridional Overturning Circulation, a shift in monsoon systems or the release of methane from hydrates) cannot be excluded. In general there is a better understanding of the consequences of crossing such thresholds than where exactly these thresholds may be ${ }^{13}$.

Aggregated globally, most changes in the physical climate system are unlikely to be strongly nonlinear below a warming of $4{ }^{\circ} \mathrm{C}$, but the impacts and risks probably are (Fig. 2e, ref. 17). Small changes locally may even be beneficial, for example, for agriculture, but impacts and damage costs increase rapidly for high levels of warming. On the other hand, mitigation costs increase rapidly towards low temperature targets. Impacts at different levels of climate change vary widely in character, time and space and are loaded with major uncertainties.

In our view, the current $2{ }^{\circ} \mathrm{C}$ UNFCCC target is a compromise between what is deemed possible and desirable, rather than a "planetary boundary" 20,21 that clearly separates a 'safe' from a 'dangerous' world.

One major challenge is that a warming of $2{ }^{\circ} \mathrm{C}$ sounds like a small change and conveys no sense of urgency to the non-expert, and quantifying its local implications is fraught with uncertainties. Even relatively straightforward variables such as local temperatures and precipitation vary widely across all land areas for a global $2^{\circ} \mathrm{Clevel}$, with local annual mean warming up to $5^{\circ} \mathrm{C}$, and local precipitation changes exceeding the range from -20 to $+30 \%$.

Uncertainties also increase towards stronger climate change both globally ${ }^{22}$ and locally, illustrated for the water cycle in Fig. 3. It shows the land fraction experiencing a trend towards wetter and drier conditions in precipitation $(\mathrm{P})$, evaporation $(\mathrm{E}), \mathrm{E}-\mathrm{P}$, soil moisture, runoff and atmospheric relative humidity combined. For a warming of $1{ }^{\circ} \mathrm{C}$ globally, about $30 \%$ of the land area and variables show a consistent change across the latest set of climate model simulations (Coupled Model Intercomparison Project Phase 5, CMIP5); for about $50 \%$ of the land the changes are within natural variability, and for about $20 \%$ of the land the models show significant changes but disagree on the sign or magnitude, with potentially unknown impacts and risks. For a warming of $3{ }^{\circ} \mathrm{C}$, that fraction of land with unknown risks more than doubles to about $50 \%$ mostly at the expense of the area with no significant change. While there 

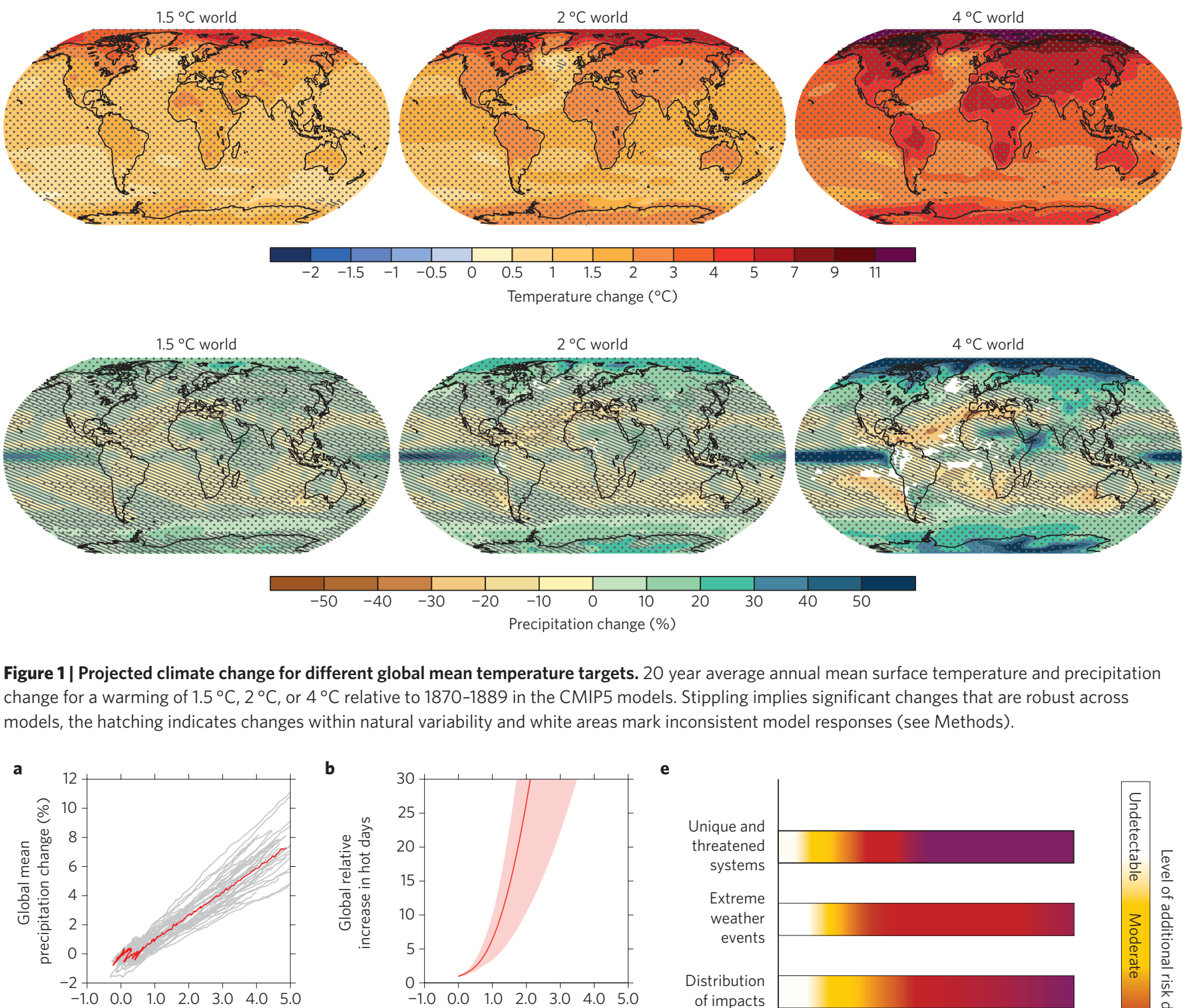

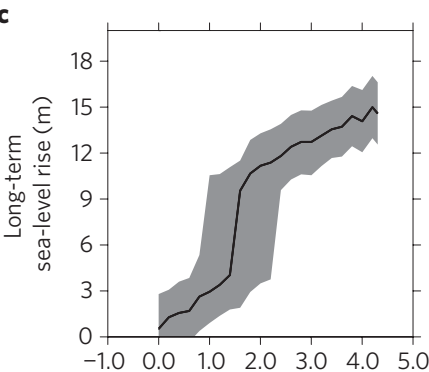

Global mean temperature change $\left({ }^{\circ} \mathrm{C}\right)$ d

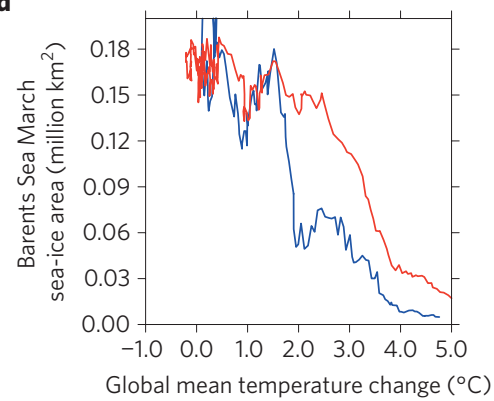

e

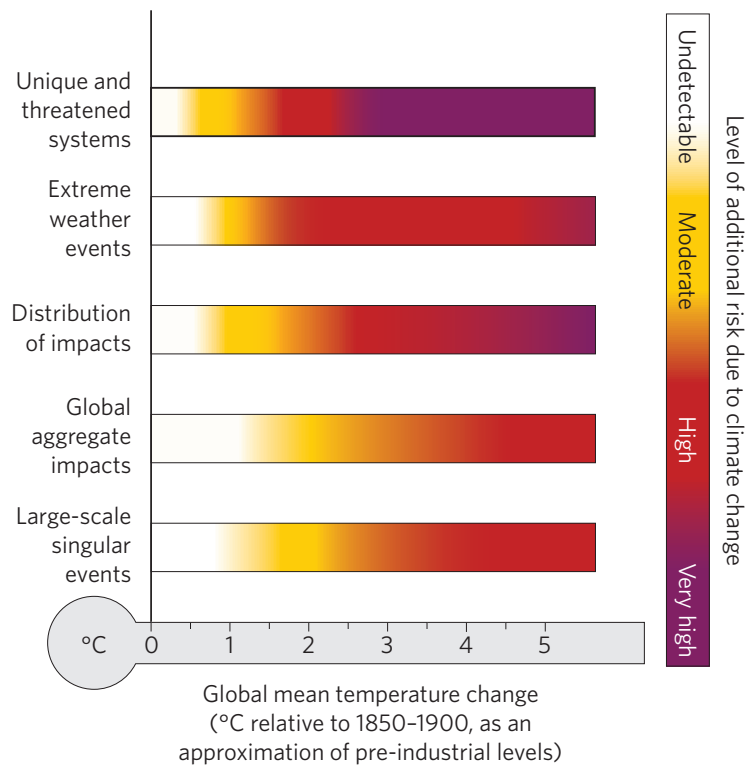

Figure 2 | Dependence of different quantities on global mean surface temperature change. a, Global annual mean change in precipitation for each CMIP5 model (grey) and the mean (red). b, Relative increase in the number of hot days (mean and CMIP model uncertainty, from ref. 16). c, Near equilibrium sealevel rise (data from ref. 13). d, Change in Barents Sea March sea-ice area for two transient climate model simulations. e, Risks associated with different 'reasons for concern' at a global scale assessed by the IPCC (data from ref. 17).

is relatively good agreement on some changes in the hydrological cycle - for example, mean and heavy precipitation ${ }^{22,23}$ — changes in soil moisture, droughts and runoff are very uncertain ${ }^{24}$.

The main challenges for science are to map out more quantitatively what the local impact of a global $2{ }^{\circ} \mathrm{C}$ warming would be, how that differs from $1.5{ }^{\circ} \mathrm{C}$ or $2.5^{\circ} \mathrm{C}$, how these impacts change over time, and what could be avoided by adaptation at what cost.
The main challenge for society is to agree on what risks are acceptable and which are to be avoided. Those risks are inherently local and sector-specific, and poorly reflected in summary figures such as the "reasons for concern"25 (Fig. 2e). Second, local decision-makers need to aggregate local risks to a global actionable target that can be discussed at the global scale. This discussion has important ethical dimensions: if the risk is high in some places and low in others, can 


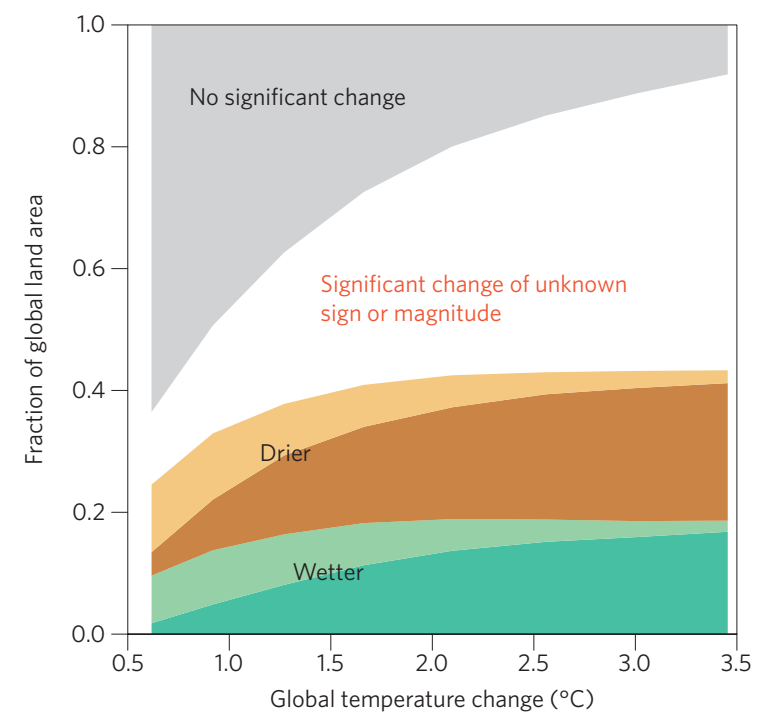

Figure $\mathbf{3}$ | Changes in the water cycle. Area showing a change towards wetter or drier conditions in precipitation (P), evaporation (E), E-P, relative atmospheric humidity, soil moisture and runoff, aggregated for winter and summer (data from ref. 24). Lighter brown and green indicate robust but non-significant changes across models, darker colours indicate robust significant changes (see Methods). Grey indicates changes within natural variability, corresponding to the hatching in Fig. 1. White indicates significant changes in individual models but disagreement on sign or magnitude across models, implying unknown risks.

we simply take a global average, accepting that half will live dangerously? Should we alternatively avoid all the risks, in which case we probably have already passed the safe limit?

\section{Timescales and reversibility}

It is unclear whether temperature targets should be interpreted as a threshold that must not be exceeded, or as an eventual long-term goal, in which case it may be exceeded temporarily. Exceeding a temperature threshold occurs if emissions are not reduced quickly enough (either for political and technological reasons, or because the climate response to forcing is higher than currently expected), or if at some point the agreed target is reduced. A warming of $1.5^{\circ} \mathrm{C}$ for example is unlikely to be achievable without an overshoot given historical and current trends in $\mathrm{CO}_{2}$ emissions ${ }^{2}$ and climate. This raises the issue of reversibility of climate change and impacts.

The climate responds to emissions on many timescales. Initially, surface warming approximately follows accumulated $\mathrm{CO}_{2}$ emissions, and water vapour, lapse rate, albedo and cloud feedbacks approximately scale with temperature. But on timescales of many centuries, additional feedbacks due to vegetation changes, or melting ice sheets and permafrost may cause additional warming. Those processes are not currently simulated in most climate models, yet may increase the canonical equilibrium climate sensitivity, assessed as 'likely' $1.5-4.5^{\circ} \mathrm{C}$ for a doubling of the atmospheric $\mathrm{CO}_{2}$ concentration, to an Earth system sensitivity on timescales of millennia to $6^{\circ} \mathrm{C}$ or more ${ }^{26,27}$.

If $\mathrm{CO}_{2}$ emissions were stopped immediately, most of the warming and therefore impacts would persist for many centuries ${ }^{28}$. This 'irreversibility' on timescales of at least hundreds of years implies that climate change from past emissions - even in the absence of future emissions - constitutes a commitment for many generations. These irreversibility concepts are often misunderstood. Some changes are irreversible in the sense that multiple equilibria exist in a dynamical system, for example, species going extinct, or the disappearance of the Greenland ice sheet (which may only regrow in climate conditions colder than today). On the other hand, most changes will simply persist for centuries to millennia due to the long lifetime of $\mathrm{CO}_{2}$ in the atmosphere. Similarly, sea-level rise would also continue for centuries under constant surface temperatures and is not easily reversed ${ }^{29}$.

Despite the committed warming, the majority of future warming is in principle not unavoidable, as future changes are determined largely by future emissions, which themselves are dependent on current investments in infrastructure ${ }^{30,31}$. Emission reductions slow down the warming trends within years ${ }^{32}$. Despite the above irreversibility considerations reverting to a substantially cooler climate is possible in principal, but only if $\mathrm{CO}_{2}$ were to be taken actively out of the atmosphere and sequestered, an operation that is still far from common practice. The timescales involved in the climate and carbon cycle are similar for warming and cooling. To first order the warming and cooling per ton of $\mathrm{CO}_{2}$ are also similar, but the release of $\mathrm{CO}_{2}$ from permafrost could cause hysteresis in the system, so additional $\mathrm{CO}_{2}$ removal would be required to compensate for that ${ }^{33}$.

In summary, climate change is not a trial-and-error experiment where a given mitigation and adaptation strategy can be tested, and choices can easily be reverted and changed if it fails. Decisions made today will partly lock the world into a pathway for decades to centuries, because the response timescales of the climate, society, and in terms of infrastructure, for instance, are long ${ }^{34}$. Temperature in scenarios without mitigation may continue to increase beyond the commonly discussed 2100 time horizon, with multimetre sealevel rise as one of the consequences. Many choices of today are therefore effectively resulting in irreversible consequences for the coming centuries.

\section{Picking a target}

Defining a climate target, and deciding who needs to do how much to achieve it, are normative problems that depend on values and world views, on arguments about fairness and on ethics. But science can and should contribute to this discussion and point out the consequences of different proposals $s^{35-37}$.

Some of the very early work has motivated the characterization of a 'safe climate' by looking at variations in past climate ${ }^{38,39}$, and this historical perspective is still relevant ${ }^{27}$; a warming of more than $2{ }^{\circ} \mathrm{C}$ would exceed temperature levels of the past several million years, and would move climate outside the bounds of the epoch in which our society developed. A comparison with the past is relevant for natural systems, but not straightforward for human systems. Our technologies for reducing risks are now much more advanced than just a century ago. On the other hand, the planet today also needs to sustain more than seven billion people, a number that is still growing. There is no doubt that unmitigated climate change will take us outside a climate regime that humanity has experienced. It is extremely likely that most of the warming since about 1950 is human-induced ${ }^{13}$, and it is therefore in our control to either halt it or let it go unmitigated.

The $2{ }^{\circ} \mathrm{C}$ target as a policy goal can be traced back to the early $1990 \mathrm{~s}^{40}$. The IPCC frames the discussion in terms of risk, and finds high risks associated with warming above $2{ }^{\circ} \mathrm{C}$. The IPCC has also laid out the normative issues, but is not defending a target because its mandate does not allow it to be policy-prescriptive. Some individual scientists are more outspoken and find even the $2^{\circ} \mathrm{C}$ target "utterly inadequate" ${ }^{\text {"25 }}$, or state that "it would seem difficult for the risk averse among us to accept anything much above that $\left[1^{\circ} \mathrm{C}\right]$ as the standard for DAI [dangerous anthropogenic interference]" ${ }^{\prime 4}$. Most of the literature, however, stops after a list of ethical dimensions and possible criteria, and leaves open the question of how to balance risk against feasibility and mitigation costs. The scientific community has been remarkably silent on defending specific climate targets. One reason is certainly that attempts to have an honest and respectful discussion about climate change, even if values are made explicit ${ }^{8}$, often turn into an ideological fight, dominated by opinions of what needs 


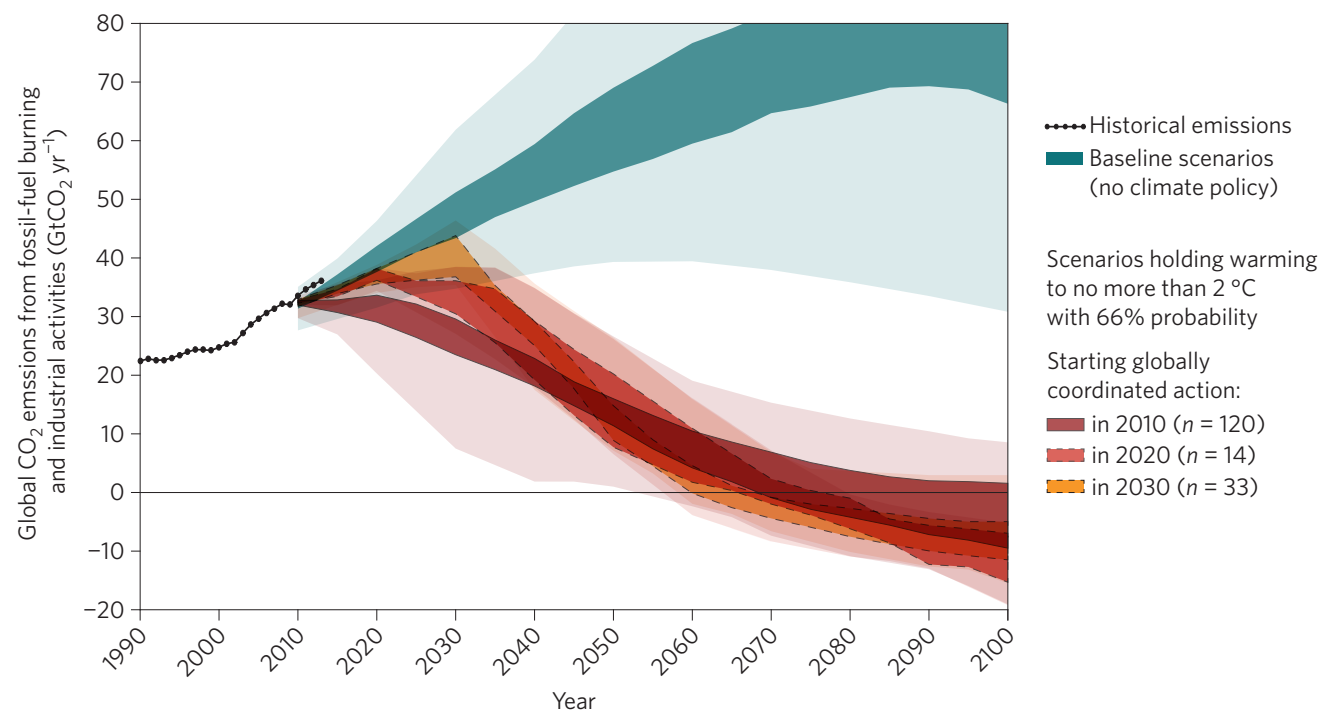

Figure 4 | Historical and future global $\mathrm{CO}_{2}$ emissions from fossil-fuel burning and industry-related activities. The thick black line shows historical data until 2013 (data from ref. 48). Orange to red coloured areas represent filtered subsets of the IPCC AR5 scenario database that are in line with limiting warming to below $2{ }^{\circ} \mathrm{C}$ during the twenty-first century with at least $66 \%$ probability. $2^{\circ} \mathrm{C}$-compatible scenarios are filtered based on the time when they assume globally coordinated climate action. Lighter shading represents the minimum-maximum range. Darker shading shows the interquartile range.

to be done about it. Attempts to discredit scientific reputations are not uncommon. Whether people are concerned about and willing to act on climate change is largely unrelated to education and the availability of information, but strongly determined by the views of those around us with which we share close ties ${ }^{42}$.

In summary, the choice of any target is ultimately a compromise between costs, benefits, trade-offs, and risks, where scientific evidence is combined with moral and ethical arguments - much like agreeing on a single speed limit on all roads. The $2{ }^{\circ} \mathrm{C}$ target is a 'focal point'43 or 'anchoring device'44 that can guide climate policy. While there are clear thresholds in some local systems, there is little evidence so far for a globally aggregated threshold that would qualify as a single planetary boundary. If it exists, we do not know yet at which level to expect it.

In a risk-averse approach such a lack of certainty on potentially catastrophic outcomes would result in even more stringent action. Recent assessments point out that the historic warming of less than $1{ }^{\circ} \mathrm{C}$ has already substantially impacted most regions and sectors around the world, and there is overwhelming evidence that unmitigated climate change would pose very high risk to both nature and society even with adaptive measure ${ }^{17}$ (Fig. 2e). More than one hundred countries now support a $1.5^{\circ} \mathrm{C}$ target ${ }^{2}$, and the most recent UNFCCC Structured Expert Dialogue concludes that "the 'guardrail" concept, in which up to $2{ }^{\circ} \mathrm{C}$ of warming is considered safe, is inadequate and would therefore be better seen as an upper limit, a defence line that needs to be stringently defended, while less warming would be preferable" 45 .

\section{Progress towards the $2{ }^{\circ} \mathrm{C}$ target}

The implications of the near-linear relationship between total $\mathrm{CO}_{2}$ emissions and temperature are simple and powerful ${ }^{36}$ : any temperature target implies a maximum carbon budget; every ton of $\mathrm{CO}_{2}$ emitted contributes to that, no matter where and when emitted; and as a consequence global emissions thus need to be near zero at some point to halt further warming. The G7 leaders recognized this in June 2015, and called for full decarbonization over the course of this century. This was widely regarded as an important political step, although from a geophysical perspective it is a trivial consequence of adhering to the agreed $2{ }^{\circ} \mathrm{C}$ target. Proposals have been made to include the year when global net emissions become zero as a UNFCCC target $^{46}$. Furthermore, net zero targets provide easyto-communicate and actionable goals ${ }^{46}$, but tracking progress over time remains critical.

For the $2{ }^{\circ} \mathrm{C}$ target, $\mathrm{CO}_{2}$ emission reductions of about $50-80 \%$ by 2050 (10th to 90 th percentile range relative to 2010 levels) are estimated in scenarios that minimize costs over the entire twenty-first century (Fig. 4). Such scenarios assume perfect foresight and participation of all countries. If emission reductions are delayed in the near term, stronger reductions are required later. The near-term evolution of emissions has important implications for the achievability of the required emission reductions later ${ }^{47}$, and warming is ultimately affected by all carbon emissions under the pathway towards zero emissions. Mitigation policies and current voluntary pledges have so far been unsuccessful in substantially changing the projected course of global GHG emissions. Current annual emissions would exhaust the carbon budget to remain below $2{ }^{\circ} \mathrm{C}$ with greater than $66 \%$ probability in about 30 years ${ }^{48}$. Furthermore, carbon intensity (the $\mathrm{CO}_{2}$ emissions per unit of energy produced) has increased again in the last decade ${ }^{49}$ - reaching near-zero carbon emissions at some point will require this to decline to zero, or carbon to be removed again from the atmosphere.

The Conference of the Parties to the UNFCCC recently noted "with grave concern the significant gap" between the emission reductions pledged and those required to meet the $2{ }^{\circ} \mathrm{C}$ target ${ }^{6}$. The world is still moving along a trajectory that can lead to $3-5{ }^{\circ} \mathrm{C}$ of warming by 2100 , and probably more after that. The effect of socalled Intended Nationally Determined Contributions (INDCs) ${ }^{50}$ has not yet fundamentally changed this assessment (Fig. 4). Whether the 'below $2{ }^{\circ} \mathrm{C}$ ' target is achievable is difficult to judge; assumptions about technological development, societal change and particularly about political will and momentum are very uncertain. Every year of delay will nonetheless narrow the options society can choose from to achieve the $2{ }^{\circ} \mathrm{C} \mathrm{goal}^{51}$, and a higher burden is put on the next generations. It will increase costs, the risks of expected and unexpected impacts, and require technologies that could come with important trade-offs. A prominent example are so-called negative emission technologies, for example, combining bio-energy production with capture and sequestration of the generated $\mathrm{CO}_{2}$.

Any climate target will be reviewed and possibly revised as scientific understanding improves and impacts are observed. The 
political debate about a lower target of $1.5^{\circ} \mathrm{C}$ at present seems to be disconnected from the level of mitigation ambition expressed by countries. But the technology and policy instruments required for limiting warming to levels lower than $2^{\circ} \mathrm{C}$ are likely to be similar to those for achieving $2{ }^{\circ} \mathrm{C}$, so the debate around the $2^{\circ} \mathrm{C}$ target should not prevent the world from making decisions and acting.

Proposed policies and actions have not yet managed to reverse past $\mathrm{CO}_{2}$ emission trends and time for avoiding dangerous levels of global warming is quickly running out. For the first time ever, however, developed and developing countries alike have initiated national processes to prepare integrated climate and development plans for submission to the UNFCCC. This is an encouraging sign, suggesting that countries are finally planning how the global transition towards climate protection can start, not only where it could end.

\section{Methods}

Methods and any associated references are available in the online version of the paper.

\section{Received 6 September 2015; accepted 16 October 2015 References}

1. The Cancun Agreements: Outcome of the Work of the Ad Hoc Working Group on Long-term Cooperative Action Under the Convention FCCC/CP/2010/7/Add.1 Decision 1/CP.16 (UNFCCC, 2010).

2. Rogelj, J. et al. Energy system transformations for limiting end-of-century warming to below $1.5^{\circ} \mathrm{C}$. Nature Clim. Change 5, 519-527 (2015).

3. Geden, O. \& Beck, S. Renegotiating the global climate stabilization target. Nature Clim. Change 4, 747-748 (2014).

4. Victor, D. G. \& Kennel, C. F. Climate policy: ditch the $2^{\circ} \mathrm{C}$ warming goal. Nature 514, 30 (2014).

5. United Nations Framework Convention on Climate Change (UN, 1992).

6. Report of the Conference of the Parties on its Eighteenth Session, Held in Doha from 26 November to 8 December 2012 - Addendum - Part Two: Action Taken by the Conference of the Parties at its Eighteenth Session FCCC/CP/2012/8/Add.1 (UNFCCC, 2012).

7. Stirling, A. Keep it complex. Nature 468, 1029-1031 (2010).

8. Schmidt, G. A. What should climate scientists advocate for? Bull. Atom Sci. 71, 70-74 (2015).

9. Steinacher, M., Joos, F. \& Stocker, T. F. Allowable carbon emissions lowered by multiple climate targets. Nature 499, 197-201 (2013).

10. Leemans, R. \& Eickhout, B. Another reason for concern: regional and global impacts on ecosystems for different levels of climate change. Glob. Environ. Change 14, 219-228 (2004)

11. LoPresti, A. et al. Rate and velocity of climate change caused by cumulative carbon emissions. Environ. Res. Lett. 10, 095001 (2015).

12. Deser, C., Knutti, R., Solomon, S. \& Phillips, A. S. Communication of the role of natural variability in future North American climate. Nature Clim. Change 2, 775-779 (2012).

13. IPCC Climate Change 2013: The Physical Science Basis (eds Stocker, T. F. et al.) (Cambridge Univ. Press, 2013).

14. Tebaldi, C. \& Arblaster, J. Pattern scaling: its strengths and limitations, and an update on the latest model simulations. Climatic Change 122, 459-471 (2014).

15. Herger, N., Sanderson, B. M \& Knutti, R. Improved pattern scaling approaches for the use in climate impact studies. Geophys. Res. Lett. 42, 3486-3494 (2015).

16. Fischer, E. M. \& Knutti, R. Anthropogenic contribution to global occurrence of heavy-precipitation and high-temperature extremes. Nature Clim. Change 5, 560-564 (2015).

17. IPCC Climate Change 2014: Impacts, Adaptation, and Vulnerability. Part A: Global and Sectoral Aspects (eds Field, C. B. et al.) (Cambridge Univ. Press, 2014).

18. Mahlstein, I. \& Knutti, R. September Arctic sea ice predicted to disappear near $2{ }^{\circ} \mathrm{C}$ global warming above present. J. Geophys. Res. 117, D06104 (2012).

19. Nordhaus, W. D. A Question of Balance: Economic Modelling of Global Warming (Yale Univ. Press, 2008).

20. Rockstrom, J. et al. A safe operating space for humanity. Nature 461, 472-475 (2009).

21. Steffen W. et al. Planetary boundaries: guiding human development on a changing planet. Science 347, 1259855 (2015).

22. Knutti, R. \& Sedláček J. Robustness and uncertainties in the new CMIP5 climate model projections. Nature Clim. Change 3, 369-373 (2013).

23. Fischer, E. M., Sedláček, J., Hawkins, E. \& Knutti, R. Models agree on forced response pattern of precipitation and temperature extremes. Geophys. Res. Lett. 41, 8554-8562 (2014).
24. Sedláček, J. \& Knutti, R. Half of the world's population experience robust changes in the water cycle for a $2^{\circ} \mathrm{C}$ warmer world. Environ. Res. Lett. 9, 044008 (2014).

25. Tschackert, $\mathrm{P} .1 .5^{\circ} \mathrm{C}$ or $2^{\circ} \mathrm{C}$ : a conduit's view from the science-policy interface at COP20 in Lima, Peru. Clim. Change Resp. 2, 1-11 (2015).

26. Knutti, R. \& Hegerl, G. C. The equilibrium sensitivity of the Earth's temperature to radiation changes. Nature Geosci. 1, 735-743 (2008).

27. Hansen, J., Sato, M., Russell, G. \& Kharecha, P. Climate sensitivity, sea level and atmospheric carbon dioxide. Phil. Trans. R. Soc. A 371, 20120294 (2013).

28. Solomon, S., Plattner, G., Knutti, R. \& Friedlingstein, P. Irreversible climate change due to carbon dioxide emissions. Proc. Natl Acad. Sci. USA 106, 1704-1709 (2009).

29. Bouttes, N., Gregory, J. M. \& Lowe, J. A. The reversibility of sea level rise. J. Clim. 26, 2502-2513 (2013).

30. Davis, S., Caldeira, K. \& Matthews, H. Future $\mathrm{CO}_{2}$ emissions and climate change from existing energy infrastructure. Science 329, 1330-1333 (2010).

31. Matthews, H. D. \& Solomon, S. Irreversible does not mean unavoidable. Science 340, 438-439 (2013).

32. Ricke, K. L. \& Caldeira, K. Maximum warming occurs about one decade after a carbon dioxide emission. Environ. Res. Lett. 9, 124002 (2014).

33. MacDougall, A. H, Avis, C. A. \& Weaver, A. J. Significant contribution to climate warming from the permafrost carbon feedback. Nature Geosci. 5, 719-721 (2012).

34. Erickson, P., Kartha, S., Lazarus, M. \& Tempest, K. Assessing carbon lock-in. Environ. Res. Lett. 10, 084023 (2015).

35. Baer, P. in Climate Change Policy: A Survey (eds Schneider, S. H., Rosencranz, A. \& Niles, J. O.) Ch. 19, 393-408 (Island Press, 2002).

36. Knutti, R. \& Rogelj, J. The legacy of our $\mathrm{CO}_{2}$ emissions: a clash of scientific facts, politics and ethics. Climatic Change http://doi.org/896 (2015).

37. Raupach, M. R. et al. Sharing a quota on cumulative carbon emissions. Nature Clim. Change 4, 873-879 (2014).

38. Nordhaus, W. D. Economic growth and climate: the carbon dioxide problem. Am. Econ. Rev. 67, 341-346 (1977).

39. Siegenthaler, U. \& Oeschger, H. Predicting future atmospheric carbon dioxide levels. Science 199, 388-395 (1978).

40. Randalls, S. History of the $2^{\circ} \mathrm{C}$ climate target. WIREs Clim. Change 1, 598-605 (2010)

41. Mann, M. E. Defining dangerous anthropogenic interference. Proc. Natl Acad. Sci. USA 106, 4065-4066 (2009).

42. Kahan, D. M. et al. The polarizing impact of science literacy and numeracy on perceived climate change risks. Nature Clim. Change 2, 732-735 (2012).

43. Jaeger, C. \& Jaeger, J. Three views of two degrees. Clim. Change Econ. 3, 145-166 (2010).

44. Van der Sluijs, J., Van Eijndhoven, J., Shackley, S. \& Wynne, B. Anchoring devices in science and policy: the case of consensus around climate sensitivity. Soc. Stud. Sci. 28, 291-323 (1998).

45. Report on the Structured Expert Dialogue on the 2013-2015 Review FCCC/ SB/2015/INF.1 (UNFCCC, 2015).

46. Ad Hoc Working Group on the Durban Platform for Enhanced Action: Agenda item 3-Implementation of All the Elements of Decision 1/CP.17 Negotiating text. FCCC/ADP/2015/1 (UNFCCC, 2015).

47. Rogelj, J., McCollum, D. L., O'Neill, B. C. \& Riahi, K. 2020 emissions levels required to limit warming to below $2^{\circ} \mathrm{C}$. Nature Clim. Change 3, 405-412 (2013).

48. Friedlingstein, P. et al. Persistent growth of $\mathrm{CO}_{2}$ emissions and implications for reaching climate targets. Nature Geosci. 7, 709-715 (2014).

49. Blanco G. et al. in Climate Change 2014: Mitigation of Climate Change (eds Edenhofer, O. et al.) 351-411 (IPCC, Cambridge Univ. Press, 2014).

50. How Close are INDCs to 2 and $1.5^{\circ} \mathrm{C}$ pathways? Climate Action Tracker Update (PIK, ClimateAnalytics, NewClimate \& Ecofys, 2015).

51. Rogelj, J., McCollum, D. L., Reisinger, A., Meinshausen, M. \& Riahi, K. Probabilistic cost estimates for climate change mitigation. Nature 493, 79-83 (2013).

52. Wigley, T. M. L., Richels, R. \& Edmonds, J. A. Economic and environmental choices in the stabilization of atmospheric $\mathrm{CO}_{2}$ concentrations. Nature 379, 240-243 (1996).

53. Hoffert, M. I. et al. Energy implications of future stabilization of atmospheric $\mathrm{CO}_{2}$ content. Nature 395, 881-884 (1998).

54. Hansen, J. et al. Target atmospheric $\mathrm{CO}_{2}$ : Where should humanity aim? Open Atmos. Sci. J. 2, 217-231 (2008)

\section{Author contributions}

All authors jointly wrote the paper. J.S. produced Figs 1-3. J.R. produced Fig. 4.

\section{Additional information}

Reprints and permissions information is available online at www.nature.com/reprints. Correspondence should be addressed to R.K.

\section{Competing financial interests}

The authors declare no competing financial interests. 


\section{Methods}

Figure 1 shows CMIP5 multi-model annual mean surface temperature change and precipitation change for a 20 year period with warming of $1.5^{\circ} \mathrm{C}$ under the RCP2.6 scenario, $2^{\circ} \mathrm{C}$ under RCP 4.5 , and $4{ }^{\circ} \mathrm{C}$ under RCP8.5 relative to $1850-1869$, for the CMIP5 models. Note that those simulations are transient. Equilibrium patterns may be slightly different but such targeted simulations do not exist for most models. One initial condition member from each model is used with equal weight. Stippling indicates regions with significant changes that are robust across models $(R>0.8$, see ref. 22$)$. Hatching marks areas where at least $80 \%$ of models indicate no significant change ( $t$-test at 95\% significance). White areas are where at least half of the models show significant changes but with poor agreement among models $(R<0.5)$. The method used is identical to that described in detail in ref. 22. Figure 3 uses the same criteria with non-significance defined as $80 \%$ of the models showing no significant change, robust change for $R>0.8$ and model disagreement for $R<0.5$, as in ref. 24, Fig. 3, aggregated for all variables and both seasons. 